International Journal of Business Management and Economic Review

Vol. 5, No. 01; 2022

ISSN: 2581-4664

\title{
OPERATIONALIZING PURPOSE BETWEEN THE ACTUAL SITUATION AND AMBITION
}

\author{
Dr. Jan van de Poll ${ }^{1}$, Arshad Shamsi ${ }^{2}$, AdJan Brouwer ${ }^{3}$ and Marissa Miller ${ }^{4}$ \\ ${ }^{1}$ Managing Director at Transparency Lab B.V. (www.praioritize.com) \\ ${ }^{2}$ Head of Strategy \& Innovation at Stratex (www.stratex.nl) \\ ${ }^{3}$ Head of People \& Culture at Stratex \\ ${ }^{4}$ Senior researcher at Transparency Lab B.V.
}

http://doi.org/10.35409/IJBMER.2022.3353

\begin{abstract}
Moving an organization beyond profit-making into positively and measurably adding value to society helps such organizations to grow in many aspects: the advantages of purpose have been widely documented. To gauge how organizations plan to implement purpose, we surveyed 96 respondents - all responsible for purpose in their organizations - in 61 different Dutch organizations on their actual situation regarding such implementation and their ambition to further operationalize it in the near term. A K-means clustering of the respondents showed five clusters for the actual situation that neatly showed progression from starting with a purpose to implementing that fully. However, we saw a dichotomy between rather conservative and very aspiring ambitions when clustering the respondents' ambitions. There was no clear direction in the middle, let alone a clear migration path for implementation.
\end{abstract}

Keyword: Purpose, purpose implementation, organizational adoption, K-means clustering.

\section{INTRODUCTION}

Literature indicates why 'purpose' is of such strategic importance for many organizations. It attracts talent, develops leadership, and improves the organization's performance. Yet, literature also suggests that implementing purpose remains a challenge. The jury is still out on how to implement purpose in an organization. Hence, it's interesting to compare how various organizations approach such challenges.

\section{A work environment to attract and retain talent}

Companies undergo much restructuring, with management paying more attention to the employees and the work environment. Human resources professionals are at the forefront of this change. They are essential to re-imagining strategy for the workforce by finding and maintaining highly-skilled employees, creating a work environment that will attract, retain, and foster employees (Bartlett \& Ghoshal, 2002). A study by Janse van Rensberg et al. (2017) sought to show the effects of employees' level of flourishing at work, specifically regarding employee intentions to stay or leave a position. They found that a wide range of dimensions, including competence but also job satisfaction and meaning at work, contribute to whether an employee flourishes or not. The study further concluded that the more evidence of a "person-environment fit," the more that employee will thrive, and in turn, will be less likely to have an intent to leave. 
International Journal of Business Management and Economic Review

Vol. 5, No. 01; 2022

ISSN: 2581-4664

\section{An opportunity for employees to thrive: meaningful work}

To successfully transition into - an organizational state which the authors call - "Industry 4.0," employees must flourish at work (van der Walt \& Lezar, 2019). In their quantitative study, the authors found that "by supporting employees' psychological well-being, digital workspaces will be in a position to promote thriving at work." However, employees should not entirely rely on organizations themselves for this support. Still, rather well-being will have to be driven by the individual for them to flourish and thrive at work. In the fields of organization and business ethics, scholars have looked at the concept of meaningful work and the factors that contribute to it. The latter area focuses on meaning in moral rights, issues, and duties. Michaelson et al. (2013) have researched the links between meaningful work and morality and see many opportunities for organizations when blending these two concepts. Meaning at work is crucial for employees, even more so than pay and working conditions, leading to better performance.

But what exactly is meaningful to people, and from where do they derive this meaning? Bailey \& Madden (2016) demonstrated that meaning at work varies from individual to individual and is often deeply personal. Additionally, meaningfulness at work was not persistent but arose during specifically meaningful moments on an individual basis. Purpose and meaning in the workplace are the keys to a fully aligned organization, and leaders can have an impactful role in getting their organization to that level (Jennings \& Hyde, 2012).

\section{Improving leadership}

Organizational justice has a role in meaning and energy in the workplace (Golparvar et al., 2014). One dimension of organizational justice, particularly interpersonal justice, primarily indicates meaning at work. A study by $\mathrm{PwC}$ (2016) focused on how leaders should tackle purpose in the workplace and lead to value optimization. Mancuso (2017) looked at the domains of character, vision, wisdom, aspiration, and relationships used by the consulting firm's Managing Partners to create organizational meaning and to what degree its followers find these concepts important. The result was that each of the five domains was of relatively equal importance but that the level of importance attributed to each correlated with respondents' age. These results indicate the necessity to look further into the influence of multi-generational workforces on leadership strategies and other meaning-making domains such as purpose.

Both employers and employees recognize purpose as one of the essential factors in the workplace. The relationship between an organization's purpose and an employee's purpose could significantly affect an individual's and organization's well-being. These two realms of purpose may benefit from alignment (Savvides \& Stavrou, 2020). Even though humans seek purpose, many people still do not find meaning in their work. McLeod (2016) suggests that organizations unintentionally tear down rather than build up their employees' sense of purpose. Therefore, McLeod offers ways for leaders to revisit and benefit from the purpose in their workplace. Studies show that nearly a quarter of the workforce would be willing to take a pay cut for a job that gives them a sense of higher purpose and that those with this sense of higher purpose are more likely to have job satisfaction (Olson, 2018). Olson's study dives deeper into workplace purpose narratives to understand their relation to employee motivation and leaders' roles. 
International Journal of Business Management and Economic Review

Vol. 5, No. 01; 2022

ISSN: 2581-4664

\section{Improved organizational performance}

Pradhan et al. (2017) demonstrate a positive connection between purpose and performance, with passion as the linking factor. Therefore, the relationship between purpose and performance is indirect, with employees relying on a passion for their purpose to obtain enhanced performance. Recognizing the tension between purpose and profit will always exist. Birkinshaw et al. (2014) discuss how to balance the two within an organization's framework of goals. By studying companies with well-defined "pro-social goals," the authors discerned that organizations need certain principles, such as proper supporting systems, to make an overarching sense of purpose sustainable, especially while striving to achieve profitability. A company needs more of a purpose than just to make money to generate motivation and fulfillment in the workplace, both of which have been shown to have longer-lasting beneficial impacts (Almandoz et al., 2018). There are two types of purpose-driven firms: those based on worker camaraderie and those based on management's high degree of clarity (Gartenberg et al., 2019). Firms with both types were observed to have higher future accounting and better stock market performance, suggesting that clearly defined purpose improves performance. While businesses who pursue wealth maximization and others who seek purpose together with wealth have most often been viewed as contrasting ways to run a business, there is instead a complementarity between the two principals (Quinn \& Thakor, 2013). Understanding that higher purpose in an organization drives better performance, Quinn and Thakor's book outlines ways that businesses can shift their mindset and use purpose as a means to achieve innovation and growth.

\section{Implementation remains a challenge}

Steger (2017) looks more acutely at meaningful work - its dimensions, themes, and benefits - and gives recommendations on how employees, leaders, and organizations can further promote it. By bringing together the fields of vocational psychology, organizational psychology, and management, Dik et al. (2013) assess how a sense of fulfillment at work can withstand various work environments. Their book also outlines strategies for implementation in the workplace. Plus, organizations need to support both an individual's purpose and the organization's purpose (Rey et al., 2019). They assert that achieving a higher purpose in the workplace is not just for profits but also for creating a sustainable organization. The implementation of purpose in an organization needs to be about implementing and getting employees fully engaged in the purpose. Despite the knowledge that purpose is crucial in leadership and the workplace, many leaders still do not possess their feeling of purpose (Craig \& Snook, 2014). Their work gives leaders insight into finding their purpose and developing it to succeed. Lleo et al. (2020) propose a three-dimensional approach to purpose implementation.

The studies show that purpose will have a more significant impact if the implementation process is more intense. A specific type of stakeholder - the hypermodern individual - tends to want purpose-driven organizations and further identifies five characteristics particular to this type of individual (Dhanesh, 2020). A study done by Bajer (2016) of over 60 organizations concluded that, while each approaches purpose differently, overall, the way purpose is being implemented is unsustainable and hinders proper purpose implementation. 
International Journal of Business Management and Economic Review

Vol. 5, No. 01; 2022

ISSN: 2581-4664

\section{Objective}

This paper aims to research how managers responsible for implementing purpose in their organizations plan to operationalize their purpose and how we can measure whether they have achieved the next level. To discover how organizations plan to implement purpose, we conducted surveys with 96 respondents in 61 different organizations. Additionally, we applied a clustering technique to group survey data into a purpose 'maturity model'.

\section{METHOD}

\section{Procedure and participants}

We got 96 respondents from 61 different organizations in the Netherlands to answer a questionnaire on operationalizing their organizations' purpose. Of these organizations, $91 \%$ existed for more than ten years, $5 \%$ between 5 and 10 years, and $4 \%$ were younger than five years. And $61 \%$ had more than 500 employees, $28 \%$ had between 25 and 500 employees, and $9 \%$ had 25 employees or less. Of the respondents, $29 \%$ identified "General management" as their role versus $18 \%$ in Marketing, $15 \%$ in Human Resources, $15 \%$ in the organization's Strategy department, and the other respondents in other departments. Of the 96 respondents, $79 \%$ identified themselves as managers; the remaining 29\% were corporate staff members. All respondents were the "owner" of purpose in their organizations.

The questionnaire consisted of 40 questions on - among others - vision, communication, stakeholder management, behavior, structure, systems, leadership, and organizational alignment, all related to the purpose and inspired by the literature in the Introduction. The questionnaire was online and took approx. 15 minutes to complete. The respondents were invited to participate as part of nationwide purpose research and were given a summary report after a few weeks. In that sense, one of the reasons for respondents to participate was to benchmark their organizations.

\section{Measures}

Operationalization is essentially about change and adoption. What is the current status of purpose in an organization? And how do those who are responsible see that changing in the foreseeable future? If we make that foreseeable future even more concrete: where do respondents see the priorities in, say, the next six months. Hence, we forewent the traditional Likert survey in favor of questions using a Guttman scale for employee polling (van de Poll, 2018 and 2021). Guttman scaling works with "current-status data" (Diamond, McDonald, and Shah, 1986), where every following answer is better than the previous one. How far is an organization on a continuum from not so good to better to even better: so-called breaking points (Uhlaner, 2002). A part of the Guttman-Poll scale is the addition of a dimension of time. For example:

What is the key driver of your organization? Now In 6 months

1. Make a profit

2. Make a profit in a responsible way

3. Have a measurable, positive impact on society, for which profit is an enabling factor

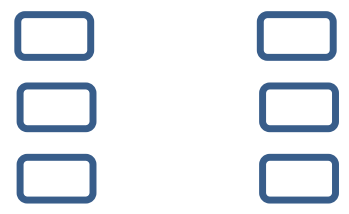




\section{International Journal of Business Management and Economic Review}

Vol. 5, No. 01; 2022

ISSN: 2581-4664

The questionnaire's answers were designed to ask for verifiable facts or verifiable behavior. Therefore, respondents provide answers considered 'objectively real' or 'a testable proposition' (Ahrens \& Chapman, 2006). Where possible, we eliminated non-verifiable adjectives and adverbs to reduce interpretation bias. And we added words like, e.g., 'formally, 'documented,' 'measurable,' 'periodically,' and 'described' to reduce respondent self-report bias (a bias discussed by Donaldson and Grans-Vallone, 2002). Additionally, such words help with verification and prevent employees from adding cognitive or emotional meaning (cf. Frese \& Zapf, 1988). We need 'binary (no/yes), numerical or categorical representations' for our intended clustering' (Plewis \& Mason, 2007). In that light, we could say that this way of formulating answers is a 'no/yes' check for categories: "Yes, we responsibly make a profit but, no, we do not formally measure the impact in society." However, subjectivity remains. The questions and answers are subjectively chosen. And the best answer, as used in a question, is not theoretically the best answer.

\section{Data analysis}

The purpose questionnaire's questions all had three answers, counted as 1,2, and 3 . The resulting matrix was 96 rows (respondents) by 40 columns (questions). Each 'cell' in the matrix contained either an answer $(1,2$, or 3 ) or no value (the respondent had skipped the question). We applied a k-means algorithm to cluster the respondents. We fixed the number of clusters to five, bypassing the standard elbow- or silhouette method. Instead, we did 10,000 iterations and calculated per iteration the improvement (if any) in the maximum distance over the clusters' 40 questions. Each respondent belonged to one cluster resulting in a frequency table for the 5 clusters.

We postulated that the worst answer scored 0 points, the middle answer 5 points, and the best answer 10 points. In this way, we translated the clustered answers into an overall cluster score. We executed this procedure twice: one time for the actual scores and one for the ambition scores. Next, we took the top-10 questions where the distance among the clusters was the largest. In other words, these were the questions where the clusters differed the most. A difference between clusters was how they had implemented purpose in their organization. We expressed that extent in the overall score: the more an organization had done, the higher the score. We found that the clusters differed more in the amount of work done than in the composition of that work. Consequently, the clusters formed a maturity model.

As k-means is a form of unsupervised learning, we labeled the clusters ourselves. And we did this again for both the actual- as the ambition clusters. Finally, having each respondent belong to a cluster for the actual and ambition scores, we made a Sankey diagram to see the action's operationalization (Fig. 1). Sankey diagrams are very good at showing particular kinds of complex information, such as how respondents move from their actual cluster to their ambition cluster. In the Sankey diagram, the number of respondents determined the clusters' width and the flow's width between these clusters. 


\title{
3. RESULTS
}

The five clusters for the actual situation are summarized in Table 1.

\author{
Table 1: Five clusters - ACTUAL SITUATION
}

Cluster 1 - PURPOSEPHOBY Share: $31 \%$ Score 3.1

1. What do core values mean for your organization?

2. What does your organization do when things are less financially?

3. How are errors dealt with within your organization?

4. How are internal messages (about teams or organization) communicated?

5. How is responsibility handled in your organization?

6. How is the organizational purpose safeguarded in the annual plans? Our core values don't mean much in practice.

7. How is the purpose of your organization safeguarded in the HR processes?

8. How is the organization purpose supported by the Supervisory Board (SB)?

9. How does your organization deal with the health and vitality of employees?

10. How does your organization deal with the happiness of employees? We do everything to become financially healthy again in the short term by cutting costs. There is no open communication about mistakes for fear of negative consequences. Employees are informed on a need-to-know via formal messages from management. It is the task of management to hold employees accountable for their responsibility. Purpose is currently not guaranteed in the annual plans.

Purpose is currently not guaranteed in the HR processes.

The SB is mainly focused on making a profit; sometimes difficult to achieve our purpose.

Health is everyone's own responsibility. Happiness is everyone's responsibility.

Cluster 2 - PURPOSE SCEPTIC Share: 11\% Score 3.3

Same answers as Cluster 1, except ...

3. How are errors dealt with within your organization?

Errors are discussed with the manager but not with the team.

4. How are internal messages (about teams or organization) communicated?

Management communicates both positive and negative messages; no room for feedback.

5. How is responsibility handled in your organization? Our organization ensures that people take responsibility using (financial) rewards.

Cluster 3 - PURPOSE OPPORTUNISTS Share: $28 \%$ Score 5.6

Same answers as Cluster 2, except ...

1. What do core values mean for your organization?

We act according to our core values.

2. What does your organization do when things are less financially?

6. How is the organizational purpose safeguarded in the annual plans?

We toptimize our existing products/services and deal responsibly with our employees.

9. How does your organization deal with the health and vitality of employees? Depends on a middle manager whether the organizational plan translates into an annual plan.

10. How does your organization deal with the happiness of employees?

The organization offers a vitality program that you can use as needed. The organization invests in the happiness of employees.

Cluster 4 - PURPOSE EXPLORER Share: 8\% Score 7.6

Same answers as Cluster 3, except...

1. What do core values mean for your organization?

3. How are errors dealt with within your organization?

4. How are internal messages (about teams or organization) communicated?

5. How is responsibility handled in your organization?

7. How is the purpose of your organization safeguarded in the HR processes?

8. How is the organization purpose supported by the Supervisory Board (SB)?

Our core values reinforce our higher purpose.

We discuss mistakes with everyone and see this as an opportunity to learn and / or improve.

In addition to transparent communication, there is room for dialogue and feedback.

Employees feel themselves responsible for their work; normal to hold each other to account.

Purpose only plays a role in performance management.

The SB is purpose-driven and supports the organization to propagate the purpose.

Cluster 5 - PURPOSE DRIVEN Share: $21 \%$ Score 8.8

Same answers as Cluster 4, except ....

2. What does your organization do when things are less financially?

6. How is the organizational purpose safeguarded in the annual plans?

7. How is the purpose of your organization safeguarded in the HR processes?

9. How does your organization deal with the health and vitality of employees?

10. How does your organization deal with the happiness of employees?

Focus on long-term value creation and stop activities that do not add value to purpose. The annual plan of each department clearly describes how it contributes to our purpose. Purpose is safeguarded in all $\mathrm{HR}$ processes, from the first contact to leaving employment. The vitality of employees is seen as very important and is anchored in the policy. Employee happiness is seen as very important and is anchored in policy.

The five clusters move through the scores show a neat progression: $3.1 \rightarrow 3.3 \rightarrow 5.6 \rightarrow 7.6$ 8.8. We named the worst scoring cluster (3.1 on a scale from $0-10)$ purposephoby, where its purpose is hardly present and left to everyone's responsibility. of the respondents, $31 \%$ scored closest to this cluster. On the other end of the spectrum, purpose-driven scored 8.8 , and $21 \%$ of 
respondents achieved this cluster. The other clusters as purpose-skeptic, purpose opportunist, purpose explorer remain in between with scores 3.3, 5.6, and 7.6.

The five clusters for ambition are summarized in Table 2.

Table 2: Five clusters - AMBITION

Cluster 1 - PURPOSE DISCOVERER Share: $40 \%$ Score 4.7

1. How does your organization deal with internal changes?

2. How is the organization purpose supported by the Supervisory Board (SB)?

3. How does your organization deal with the happiness of employees?

4. Is your organization working on new business models to better serve the purpose?

5. How is the purpose of your organization safeguarded in the HR processes?

6. What value do the products and / or services of your organization add?

7. What is the vision of your organization on sustainability?

8. I what degree does sustainability live within your organization?

9. How does your organization communicate about sustainability?

10. How does your organization deal with the interests of the various 'stakeholders'?
Change is introduced and implemented top-down.

The SB is primarily focused on making a profit, which is in line with our organizational objectives. Happiness is everyone's responsibility.

We do not look at new business models.

Purpose only plays a role in performance management

Our products and / or services create clear value for the customer.

Our aim is to limit/neutralize the negative impact of our activities on the environment and people.

Most colleagues find sustainability important, but performance objectives are even more important.

We communicate about our sustainability policy in our marketing.

We are focused on the interests of shareholders, customers, and our employees.

Cluster 2 - PURPOSE MARKETEER / WASHER Share: $13 \%$ Score 6.7

Same answers as Cluster 1, except ...

1. How does your organization deal with internal changes?

2. How is the organization purpose supported by the Supervisory Board (SB)?

4. Is your organization working on new business models to better serve the purpose?

5. How is the purpose of your organization safeguarded in the HR processes?

7. What is the vision of your organization on sustainability?

8. I what degree does sustainability live within your organization?

9. How does your organization communicate sus ais bilty to the out

10. How does your organization deal with the interests of the various 'stakeholders'? When making decisions, we always consider the consequences for all stakeholders.

Management and employees communicate, which leads to change initiatives from both sides. The $\mathrm{SB}$ is purpose-driven and supports the organization to propagate the purpose.

We are experimenting with new business models such as circular, sharing and exchange. Purpose is currently not guaranteed in the HR processes. Our business activities should have a positive impact on the environment and people Colleagues consciously act on sustainability, as this creates value for everyone in the long term.

We communicate openly about our successes and challenges in the field of sustainability.

Cluster 3 - PURPOSE ENABLER Share: $11 \%$ Score 6.7

Same answers as Cluster 2, except

1. How does your organization deal with internal changes?

Management facilitates employees to take ownership and initiative for change.

2. How is the organization purpose supported by the Supervisory Board (SB)? $\quad$ The SB is mainly focused on making a profit; so sometimes difficult to achieve our purpose.

3. How does your organization deal with the happiness of employees?

5. How is the purpose of your organization safeguarded in the HR processes?

6. What value do the products and / or services of your organization add?

7. What is the vision of your organization on sustainability?

8. I what degree does sustainability live within your organization?

10. How does your organization deal with the interests of the various 'stakeholders'?

The organization invests in the happiness of employees.

Purpose only plays a role in performance management.

Our products and / or services create clear value for the customer.

Our aim is to limit/neutralize the negative impact of our activities on the environment and people.

Most colleagues find sustainability important, but performance objectives are even more important.

We are focused on the interests of shareholders, customers, and our employees.

Cluster 4 - PURPOSE DISRUPTOR Share: $12 \%$ Score 8.3

Same answers as Cluster 3, except

1. How does your organization deal with internal changes?

2. How is the organization purpose supported by the Supervisory Board (SB)?

3. How does your organization deal with the happiness of employees?

6. What value do the products and / or services of your organization add?

7. What is the vision of your organization on sustainability?

8. I what degree does sustainability live within your organization?

10. How does your organization deal with the interests of the various 'stakeholders'?

Management and employees communicate, which leads to change initiatives from both sides.

The $\mathrm{SB}$ is purpose-driven and supports the organization to propagate the purpose.

Employee happiness is seen as very important and is anchored in policy.

Our products/services create value for the customer as well as social/ecological value.

Our business activities should have a positive impact on the environment and people.

Colleagues consciously act on sustainability, as this creates value for everyone in the long term.

When making decisions, we always consider the consequences for all stakeholders.

Cluster 5 - SOCIAL ENTREPRENEUR Share: $24 \%$ Score 9.7

Same answers as Cluster 4, except ...

4. Is your organization working on new business models to better serve the purpose? Our entire business is in transition to a new business model.

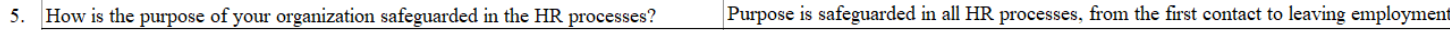

6. What value do the products and / or services of your organization add? $\quad$ Our products/services create value for the customer as well as social/ecological value.

9. How does your organization communicate sustainability to the outside world? We communicate openly about our successes and challenges in the field of sustainability 
International Journal of Business Management and Economic Review

Vol. 5, No. 01; 2022

ISSN: 2581-4664

The score progression is not as neat as the actual situation: $4.7 \rightarrow 6.7 \rightarrow 6.7 \rightarrow 8.3 \rightarrow 9.7$. The switch from Cluster 1 to Cluster 2 and then to Cluster 3, which also scores a 6.7, is remarkable. Cluster 2 (purpose marketeer/washer) focuses more on business and stakeholders, while cluster 3 (purpose enabler) on the people side of purpose: two clusters with an identical score but a different composition.

The operationalization from actual to ambition is a move from cluster to cluster and is visualized in Figure 1. The Sankey diagram shows the five clusters for the left side's actual situation and the five clusters for ambition on the right side. The lines show the migration: how the respondents view their operationalization of purpose. Most notable is the large share of Cluster 1 (purpose discoverer). Given all the positive things that purpose is supposed to bring to an organization, $40 \%$ of the respondents seem to have a very conservative ambition. Plus, it is in stark contrast with the $24 \%$ of respondents who set their eye on the other end of the spectrum as they choose Cluster 5 (social entrepreneur): a dichotomy.

Figure 1: Operationalization

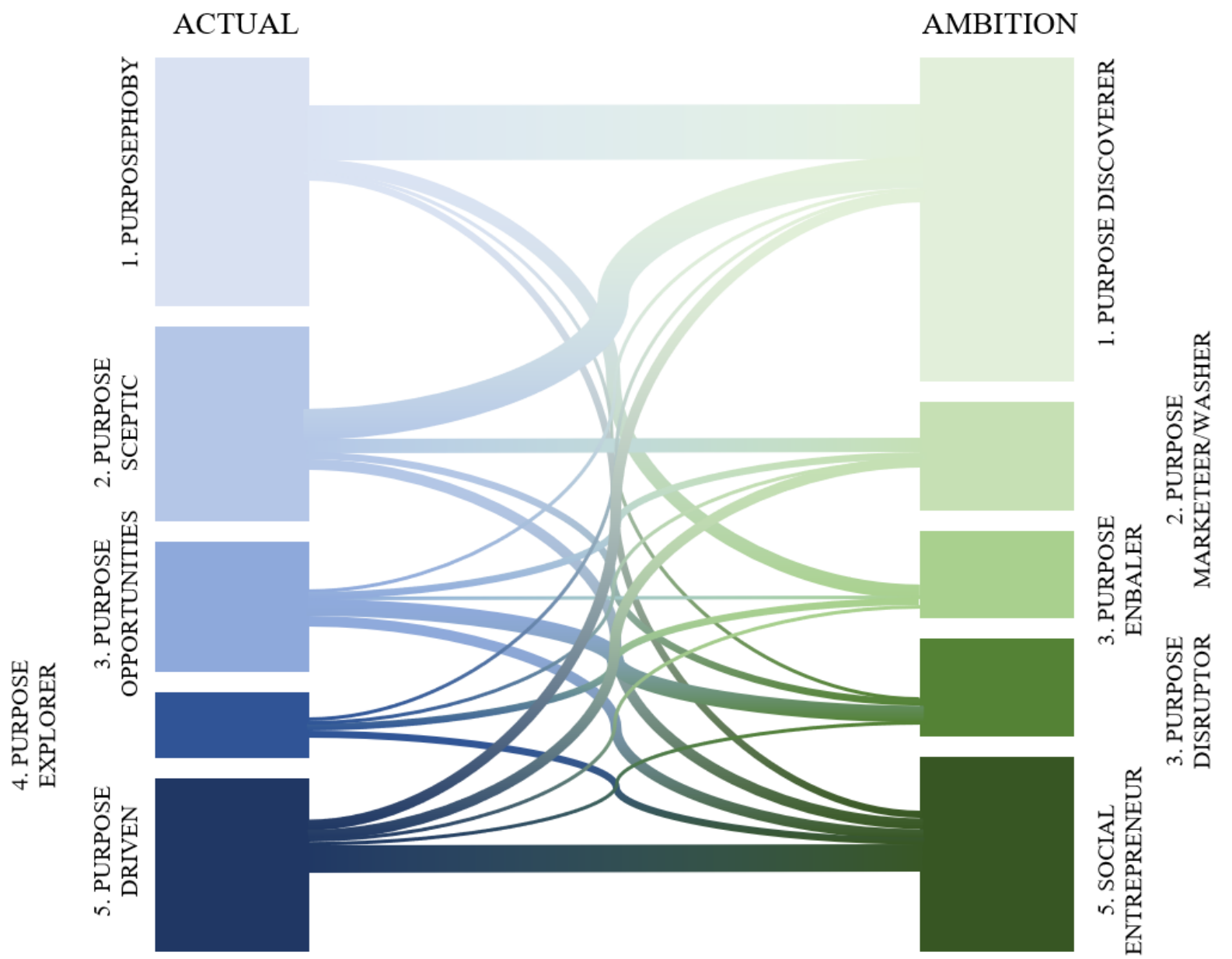


International Journal of Business Management and Economic Review

Vol. 5, No. 01; 2022

ISSN: 2581-4664

\section{DISCUSSION}

Scientific literature clarifies the benefits of purpose in an organization for employees, managers, and performance alike. It's then interesting to see to which extent organizations are implementing purpose according to a relatively objective measurement rod. The clustering of the actual situation scores shows an expected pattern of organizations just starting, some others moving ahead, and others scoring already more advanced answers.

It's the operationalization itself that is most remarkable. We see almost a dichotomy between very conservative approaches (40\% of respondents scoring Cluster 1) and very advanced approaches ( $24 \%$ of respondents scoring Cluster 5 ) strengthened by a midfield without a clear direction (either business- or people-focused).

\section{LIMITATIONS AND FUTURE RESEARCH}

Although the respondents came from diverse organizations, it's too early to conclude whether these clusters and operationalization patterns also emerge in larger respondent samples. So, organizations will always end up in some cluster. It's way more interesting to research whether these (or similar) patterns would occur within one organization. If the dichotomy, as we see in the paper, would materialize within one organization, there is a lot of internal communication and organizational alignment at hand. Yet, organizations may have different views on how to implement purpose. Managers in Cluster 5 could irritate respondents in Cluster 1 with an overzealous approach. Simultaneously, respondents in Cluster 1 could thwart people in Cluster 5 by being way too slow in implementation. Plus, the unclear midfield shows there is not a single improvement path. Hence, more research is needed within organizations. This research will result in more precision as alternative questionnaire topics can be compared. We are fully aware that our selection of 40 questions, however well-intended as a reflection of the literature, remains a subjective choice. The choice of the Guttman-Poll survey design (tallying verifiable facts/behavior rather than asking for opinions, two answers per question to create a movement that describes the operationalization) proved very useful as a data source for K-means clustering.

\section{CONCLUSIONS}

Despite the documented benefits of implementing purpose in organizations, it remains a challenge, and many organizations take a very cautionary approach in this regard. We addressed in our article what the current status of purpose in an organization is and how it changes in the foreseeable future.

We used a short online questionnaire for our nationwide purpose research in this study. A total of 96 respondents - all responsible for purpose in their organizations - in 61 different organizations in the Netherlands participated in the survey. We used K-means clustering to group the respondents. We noted that the five clusters for the actual situation neatly showed a progression from starting with a purpose to fully implementing that purpose: a maturity model. We recorded a dichotomy of very conservative and aspiring ambition for the actual situation. Objectively tallying and clustering how organizations plan to operationalize purpose will help purpose implementation roadmaps and support internal alignment. 
International Journal of Business Management and Economic Review

Vol. 5, No. 01; 2022

ISSN: 2581-4664

\section{ACKNOWLEDGEMENT}

We would like to express our appreciation to Dr. Jasna Duricic for her valuable and constructive suggestions during the planning and development of this research.

\section{REFERENCES}

Ahrens, T., \& Chapman, C. S. (2006). Doing qualitative field research in management accounting - positioning data to contribute to theory. Accounting, Organizations and Society, 31, 819-841.

Almandoz, J., Lee, Y., \& Ribera, A. (2018). Unleashing the power of purpose: 5 steps to transform your business. IESE Insight, 37, Second Quarter, 44-51.

Bailey, C., \& Madden, A. (2016). What makes work meaningful - or meaningless. MIT Sloan Management Review, 57(4).

Bajer, J. (2016). What's the point? The search for purpose at work. Strategic HR Review, 15(1), 25-28.

Bartlett, C. A., \& Ghoshal, S. (2002). Building competitive advantage through people. MIT Sloan Management Review, 43(2), 34-41.

Birkinshaw, J., Foss, N.J., \& Lindenberg, S. (2014). Combing purpose with profits. MIT Sloan Management Review, 55(3), 49-56.

Craig, N., \& Snook S. (2014). From purpose to impact: Figure out your passion and put it to work. Harvard Business Review, 92(5), 105-111.

Dhanesh, G. (2020). Who cares about organizational purpose and corporate social responsibility, and how can organizations adapt? A hypermodern perspective. Business Horizons, 63(4), 585594.

Diamond, I. D., McDonald, J.W., \& Shah, I.H. (1986). Proportional hazards models for current status data: application to the study of age at weaning differentials in Pakistan. Demography 23(4), 607-620.

Dik, B. J., Byrne, Z. S., \& Steger, M. F. (Eds.). (2013). Purpose and meaning in the workplace. American Psychological Association.

Donaldson, S. I., \& Grans-Vallone, E. J. (2002). Understanding self-report bias in organizational behavior research. Journal of Business and Psychology 17(2), 245-260.

Frese, M., \& Zapf, D. (1988). Methodological issues in the study of work stress: Objective vs subjective measurement of work stress and the question of longitudinal studies. In: C. L. Cooper, 


\section{International Journal of Business Management and Economic Review}

Vol. 5, No. 01; 2022

ISSN: 2581-4664

\& R. Payne (Eds.), Causes, Coping, and Consequences of Stress at Work (pp. 375-411). Wiley \& Sons, Chichester.

Fullerton, J. (2015). Regenerative capitalism: How universal principles and patterns will shape our new economy. Capital Institute. https://capitalinstitute.org/wp-content/uploads/2015/04/2015Regenerative-Capitalism-4-20-15-final.pdf

Gartenberg, C., Prat, A., \& Serafeim, G. (2019). Corporate purpose and financial performance. Organization Science, 30(1).

Golparvar, M., Javadian, Z., Rajezi, R., \& Rezaie, A. (2014). The relationship between perceived organizational justice with the meaning at work and feeling of energy at workplace: A structural equation modeling approach. Journal of Basic and Applied Scientific Research, 4(2), 87-96.

Janse van Rensberg, C., Rothmann, S. I., \& Diedericks, E. (2017). Person-environment fit, flourishing and intention to leave in universities of technology in South Africa. SA Journal of Industrial Psychology, 43(1), 1-10.

Jennings, K., \& Hyde, H. (2012). The greater goal: Connecting purpose and performance. BerrettKoehler Publishers.

Lleo, A., Bastons, M., Rey, C., \& Ruiz-Perez, F. (2020). Purpose implementation: Conceptualization and measurement. SSRN Electronic Journal.

Lucas, K. (2015). Workplace dignity: Communicating inherent, earned, and remediated dignity. Journal of Management Studies, 52, 621-646.

Mancuso, R. J. (2017). Leadership: A mixed-method case study to explore the behaviors a consultancy firm managing partner uses to create meaning in their leadership - for themselves and their followers - through character, relationships, inspiration, vision, and wisdom. Brandman University Dissertations, 118.

McLeod, L.E. (2016). Leading with noble purpose: How to create a tribe of true believers. John Wiley \& Sons.

Michaelson, C., Pratt, M. G., Grant, A. M., \& Dunn, C.P. (2013). Meaningful work: Connecting business ethics and organization studies. Journal of Business Ethics, 121(1), 77-90.

Olson, K. M. (2018). " I'm Helping to Put a Man on the Moon": Communicating Higher Purpose in the Workplace (Doctoral dissertation, Purdue University).

Plewis, I., \& Mason, P. (2007). What works and why: combining quantitative and qualitative approaches in large-scale evaluations. International Journal of Social Research Methodology, 8(3), 185-194. 


\section{International Journal of Business Management and Economic Review}

Vol. 5, No. 01; 2022

ISSN: 2581-4664

Pradhan, R. K., Panda, P., \& Jena, L. K. (2017). Purpose, passion, and performance at the workplace: Exploring the nature, structure, and relationship. The Psychologist-Manager Journal, 20(4), 222-245.

PricewaterhouseCoopers (PwC). (2016). Putting purpose to work: A study of purpose in the workplace. https://www.pwc.com/us/en/about-us/corporate-responsibility/assets/pwc-putting-purpose-towork-purpose-survey-report.pdf

Quinn, R. E., \& Thakor, A. V. (2013). The economics of higher purpose. ECGI - Finance Working Paper, 395. DOI: 10.2139/ssrn.2362454

Quinn, R. E., \& Thakor, A. V. (2019). The economics of higher purpose: Eight counterintuitive steps for creating a purpose-driven organization. Berrett-Koehler Publishers.

Rey, C., Bastons, M., \& Sotok, P. (Eds.). (2019). Purpose-driven organizations: Management ideas for a better world. Palgrave Macmillan.

Savvides E., Stavrou E. (2020). Purpose, meaning, joy, and fulfilment at work. In: Dhiman S. (Ed.), The Palgrave Handbook of Workplace Well-Being. Palgrave Macmillan, Cham.

Steger, M. (2017). Creating meaning and purpose at work. In Passmore, J., Oades, L., Steger, M.F., Delle Fave, A. (Eds.), The Wiley Blackwell handbook of the psychology of positivity and strengths-based approaches at work (pp. 60-81). Wiley-Blackwell.

Uhlaner, L. M. (2002). The use of the Guttman scale in development of a family business index. (No. H200203). EIM Business and Policy Research.

Van de Poll, J.M (2021). An Alternative to the Likert Scale When Polling Employees. International Journal of Business and Management, 9(5), 239-244.

Van de Poll, J.M. (2018) Ambition patterns in strategic decision-making, Doctor of Philosophy, Industrial Engineering and Innovation Sciences, Technical University Eindhoven.

van der Walt F., Lezar L.W.P. (2019). Flourishing and thriving for well-being. In Coetzee M. (Ed.), Thriving in digital workspaces (pp. 85-107). Springer, Cham.

White, A., Yakis-Douglas, B., Helanummi-Cole, H., \& Ventresca, M. (2016). Purpose-led organization: "Saint Antony" reflects on the idea of organizational purpose, in principle and practice. Journal of Management Inquiry, 26(1). 